

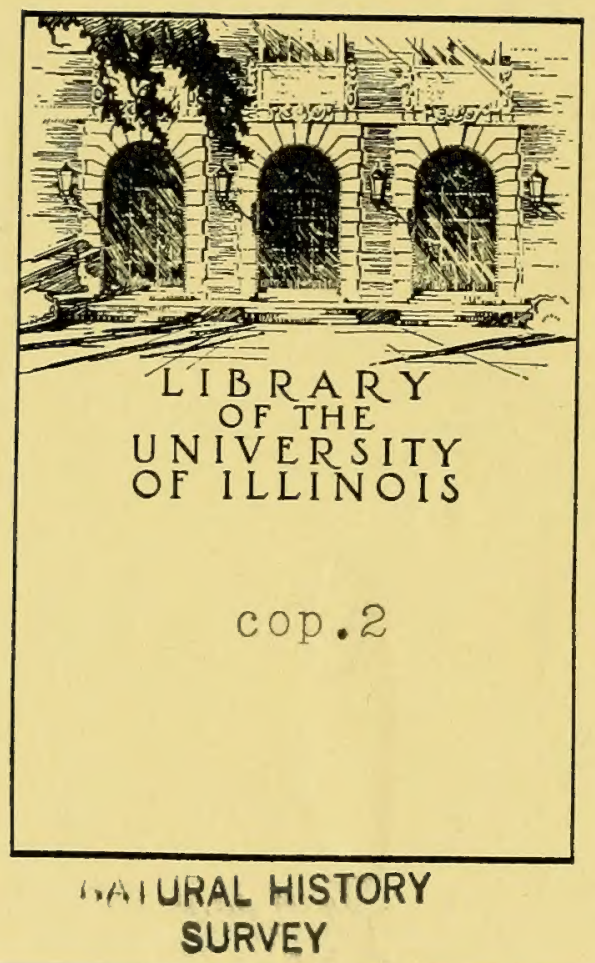






STATE OF ILLINOIS

Adlai E. Stevenson, Governor

DEPARTMENT OF REGISTRATION AND EDUCATION

C. Hobart Engle, Director

HOME POOLS AND HOMING BEHAVIOR

OF SMALLMOUTH BLACK BASS

IN JORDAN CREEK

R. Weldon Larimore

Biological Notes No. 28

Printed by Authority of the State of Illinois

NATURAL HISTORY SURVEY DIVISION

Harlow B. Mills, Chief

Urbana, Illinois

June, 1952 


\title{
HOME POOLS AND HOMING BEHAVIOR OF SMALLMOUTH BLACK BASS IN JORDAN CREEK
}

\author{
R. WELDON LARIMORE, Assistant Aquatic Biologist \\ NATURAL HISTORY SURVEY DIVISION
}

The possibility that some fresh-water fish establish home territories, definite water areas in which they spend much or most of their lives, is of considerable biological interest, not only because it presents a fascinating phase of animal behavior but also because it has implications in fish management.

Although Thompson (1933) found evidence to indicate randomness of movement among several species of fish in Illinois rivers and streams in a period of drought years, other investigators have detected among the species they studied at least temporary attachment to particular places. Shetter (1937), working with a cold-water species, brook trout in Michigan, found that at least one-third of the over-the-winter recoveries of these fish were individuals that, following the spawning run, had returned to the places where they were tagged the previous year. After following the movements of brown trout in a New York creek, Schuck (1945) stated that the larger-sized trout tended to remain in the location of their initial preference, leaving it to spawn upstream, but returning some time later. Although there is little evidence that warmwater species will return to a home territory after having left it, Scott (1949) found that rock bass in an Indiana stream tended to remain in a very limited area. Gerking (1950) showed that certain warmwater fish in an Indiana stream occupied "homes" during the summer months. He found that longear sunfish, green sunfish, and rock bass were more sedentary than smallmouths, spotted bass, or suckers.

In studying the movements of fish in relation to brush shelters, Rodeheffer (1941) considered the tendency of transferred fish to return to the place of their original capture. He moved 767 marked fish a straight-line distance of 0.6 mile across a bay of Douglas Lake, Michigan. Forty-two of these fish were later retaken, 37 at the place of original capture. Thirty of the total number of fish returning to the area of original capture were rock bass. Two of 20 smallmouths moved were recaptured, 1 at the site of original capture. Rodeheffer did not regard the results of this experiment as evidence of homing. He suggested that the recaptures made at other points in the lake

indicated that the transferred fish moved around somewhat at random.

The tendency for a fish to remain in a particular territury, or return to it after being away, appears to be intimately related to seasonal movements, maintenance of territories, temporary wandering, and general requirements of the fish. These phenomena were not investigated in the present study because of its necessarily limited scope.

With the exception of a few minor observations on longear sunfish, the investigation reported here is purposefully restricted to illustrating the attachment of the smallmouth black bass, Micropterus dolomieu Lacépède, to home pools in Jordan Creek.

\section{Evidence of home Pools in Jordan Creek}

Jordan Creek is located near Fairmount, Vermilion County, in east-central Illinois. This small stream, figs. 1 and 2, a tributary of the Salt Fork of the Vermilion River, is composed of short, hard-bottomed pools and shallow riffles, and most of it varies from 15 to 35 feet in width. Between July 25 and September 5, 1950, an initial census was made of the fish population in the lower 4 miles of the creek, which included all of its waters suitable for game fishes. Fish were collected with the aid of a 21-foot electric seine, fig. 2, similar to the one described by Funk (1949); the seine operated off a 115-volt, alternating current generator. Consecutive collections were taken at intervals upstream from the mouth of the creek.

As the fish were collected, the game and pan species were marked by fin-clipping to associate them with the 15 divisions into which the stream was marked off for study. These divisions, which varied in length from 0.11 to 0.42 mile, were established with due consideration for the natural divisions between pools. After the game and pan fishes had recovered from the effects of the electric current, they were released in the pools from which they had been taken.

Many of these divisions of the stream were reworked after the preliminary census. The game and pan fishes taken in the repeat censuses were 
marked with numbered opercular tags. Fish recaptured after having been marked either by finclipping during the original census or by tagging in later collections provided interesting information on movements and home areas of these stream species. the winter of 1950-51 in their home pools. Of the 10 that were not in the pools in which they had been taken originally, 6 were relatively short distances away, averaging 0.12 mile. Additional evidence of attachment of smallmouth bass to home

Table 1. - Recaptures of marked smallmouth bass in Jordan Creek. Each fish was fin-clipped at some time between July 25 and September 5, 1950, to identify it with the section of the stream in which it was first taken.

\begin{tabular}{c|c|c}
\hline Month of Recapture & $\begin{array}{c}\text { Number of Bass } \\
\text { Retaken in Section } \\
\text { Where Fin-Clipped }\end{array}$ & $\begin{array}{c}\text { Number of Bass } \\
\text { Retaken Outside of } \\
\text { Section Where Fin-Clipped }\end{array}$ \\
\hline August & 7 & 0 \\
September & 14 & 7 \\
October & 20 & 4 \\
November & 4 & 0 \\
Total & 45 & 11 \\
1951 & & \\
March & 2 & 0 \\
May & 12 & 7 \\
August & 25 & 14 \\
September & 4 & 2 \\
October & 8 & 2 \\
Total & 51 & 25 \\
\hline
\end{tabular}

The locations of the fin-clipped smallmouth bass that were recaptured, table 1 , indicate that part of the population remains in the same general area at least for several months of the year. Eighty per cent of the smallmouths recaptured during the late summer and fall months of 1950 were in the sections of the stream in which they had been marked. During 1951, 67 per cent of the recaptures were in the sections in which they had been taken originally. Since these recaptures did not include any tagged fish, the individuals considered here were, with possibly a few exceptions, only those marked during the original 1950 census. The possible exceptions were a few smallmouth bass recaptured late in 1951 that had been taken earlier in the year but that perhaps had lost their tags.

Attachment of smallmouth bass to home pools was indicated by recaptures of tagged fish in 1951 . Two hundred thirty-nine smallmouth bass were tagged during the period subsequent to the original census and previous to October, 1951. During 1951, 25 of these bass were retaken. Fifteen of them (60 per cent) were in the pools in which they had been tagged. Of these, 5 apparently had passed pools was supplied by recovery of many more of the tagged fish early in 1952.

\section{Experiments on Homing Behavior}

Three experiments were planned to test the homing behavior of smallmouth bass in Jordan Creek. For these experiments, pools were selected that contained fair numbers of smallmouths and that were distinctly isolated by shallow riffles. In each experiment, the bass were taken from one pool, assumed to be the home pool, given numbered opercular tags, and transferred by truck to another previously selected pool. Two experiments were started the last week in September, 1950, the third in early October of the same year. At intervals of 1 or 2 weeks from the beginning of these experiments until the stream was frozen over in November, the pools from which the smallmouths had been removed were examined for returned fish. Late in the fall the pools that had received the transferred smallmouths also were examined (with the exception of pool II, 2, mentioned later) for fish that might 
have remained there. No systematic search was made for transferred smallmouths in other parts of the stream, although several were collected incidentally during other investigations.

\section{Experiment $A$}

The objective of this experiment was to test the ability of smallmouth bass to return to a home pool after having been moved upstream. The pool in which a fish was first taken was assumed to be the home pool for that fish. Each time a fish was retaken in its home pool it was to be transferred again to the upstream pool to which it had been moved.

On September 28, 1950, five bass were taken from pool VI, 8, tagged, transported overland by truck, and released upstream in pool IX, 3, fig. 1, a distance of 0.66 mile by water. There were 14 shallow riffles and 13 pools between pool VI, 8, and pool IX, 3. The returns from this first transfer are shown in fig. 3. Since most of these fish, plus two others not taken in the first collection, were transferred several times, making their movements difficult to follow, a brief case history is given for each fish.

Bass No. 145 (total length 10.9 inches) was transferred upstream September 28 and recovered 1 week later, October 6 , in its home pool. At this time, it was again moved upstream. On October 20 , 2 weeks after the second transfer, it was collected 0.14 mile upstream from the point of release.

Bass No. 147 (total length 11.9 inches) was first transferred upstream September 28; it was retaken in its home pool 1 week later, October 6 , and was again transferred upstream. One week later, October 13, it was again recaptured in its home pool and was again transferred upstream. It was not found in the home pool on October 20 but was there several months later, March 6, 1951. The movements of this fish are shown by a diagram, fig. 4.

Bass No. 143 (total length 13.3 inches) was first transferred upstream on September 28. It had returned to its home pool by October 13 and was again transferred. One week later, October 20, it was still at the point of release upstream from its home pool. Although no fish bearing tag No. 143 was retaken after this date, an untagged fish of the same size, and with the same clipped-fin mark, was caught halfway between these two pools on May 16,1951 , and was retaken in the home pool of No. 143 on August 10, September 17, and October $17,1951$.
Bass No. 144 (total length 14.6 inches) was moved upstream September 28. The following week it was not found in its home pool, but on October 13 it was collected 0.40 mile downstream from its home pool and 1.06 miles below the place of release 2 weeks before. It was then transported along with other fish (described in Experiment B) 0.81 mile farther downstream. One week later, October 20, it was found in its original home pool, having returned 1.21 miles upstream. On this date it was again transferred to the upstream pool. Although it was not recaptured in the home pool on November 14, it was retaken there the next time the pool was examined, March 6, 1951.

The remarkable movements of this fish are shown in fig. 3. Why this fish overshot its home pool on its first downstream movement is unexplainable, for it returned rapidly upstream to its home pool when carried farther downstream.

Bass No. 146 (total length 11.7 inches) was not recaptured in pool VI, 8, the pool from which it was taken for transfer upstream on September 28, nor was it found later in the upstream pool in which it was released. The fin mark of this fish when it was taken on September 28 indicated that it had been marked previously in another section of this stream. It may have been only a temporary resident of pool VI, 8; possibly it should not have been expected to return there after having been moved.

Bass No. 141 (total length 10.7 inches) was transferred upstream October 6 and retaken after 1 week, October 13, in the home pool. Then, after its second transfer, it was recaptured at the upstream point of release on October 20 and March 6, 1951 , apparently having overwintered in that pool.

Bass No. 199 (total length 10.2 inches) was moved upstream on October 6 and was not retaken either in the pool in which it was captured nor in the pool in which it was released.

Of the seven fish moved 0.66 mile upstream, apparently two never returned to the pool in which they were taken, two returned once but not a second time, and three returned every time moved (one, three times; two, two times). Thirteen transfers were made, nine of which were followed by homing responses.

\section{Experiment B}

This experiment was planned to test the ability of smallmouth bass to return to a home pool after having been transferred downstream. Seven smallmouths $(11.4,11.2,10.5,11.8,13.5,11.3$, and 7.5 inches total length) were taken from pool V, 11, figs. 2 and 3, on October 13, 1950, and transferred 


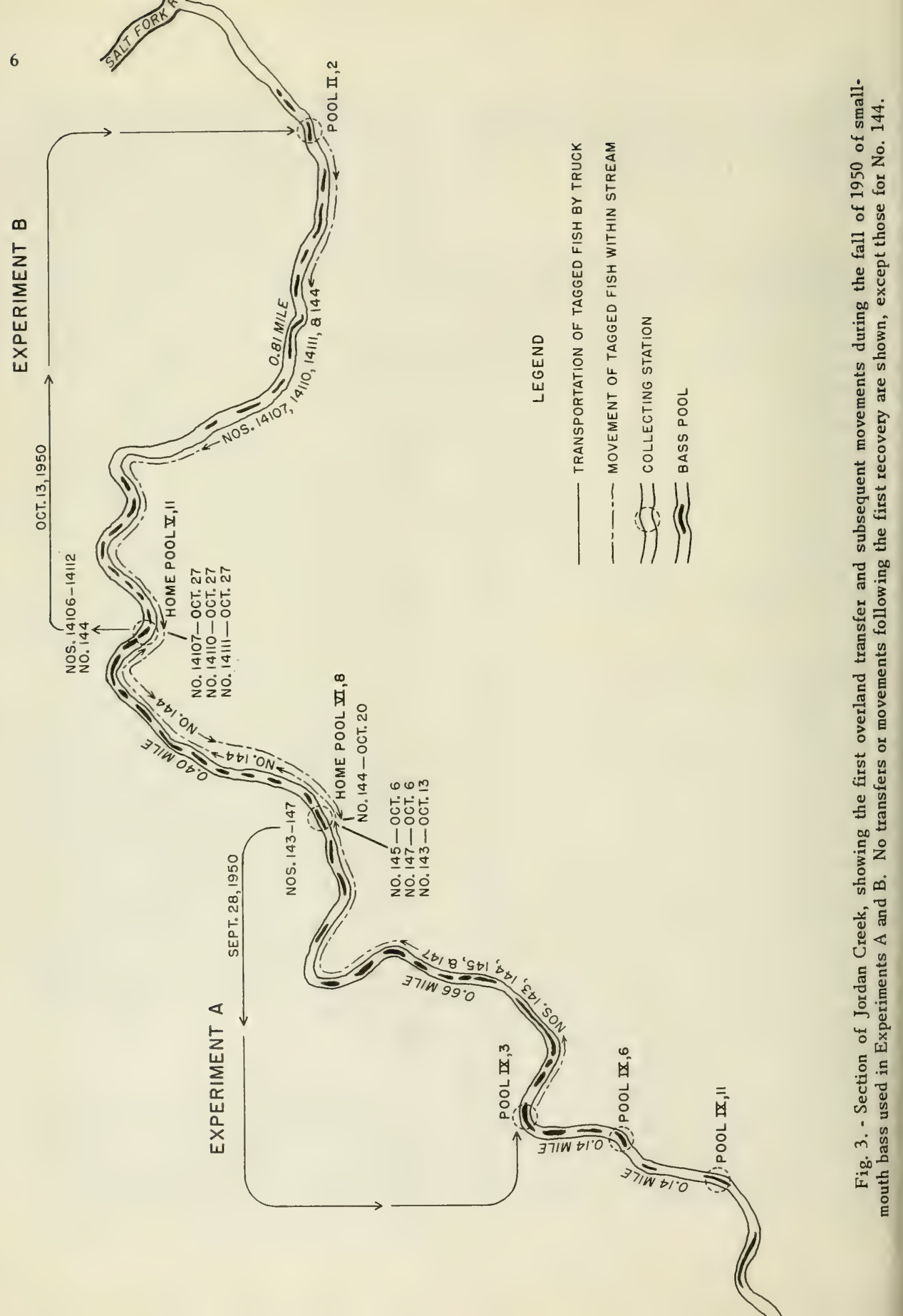


by truck downstream to pool II, 2. The distance between pools of 0.81 mile by water included 20 shallow riffles and 19 pools, 16 of the pools especially suitable for bass. Two weeks later, October 27, the home pool was censused.

The simplicity of this single transfer makes it possible that, if this pool had been worked more than the one time during the fall, a higher percentage of these bass might have been recovered. Evidence substantiating this assumption was found in recensusing this pool during August, September, and October, 1951. In these three censuses 16

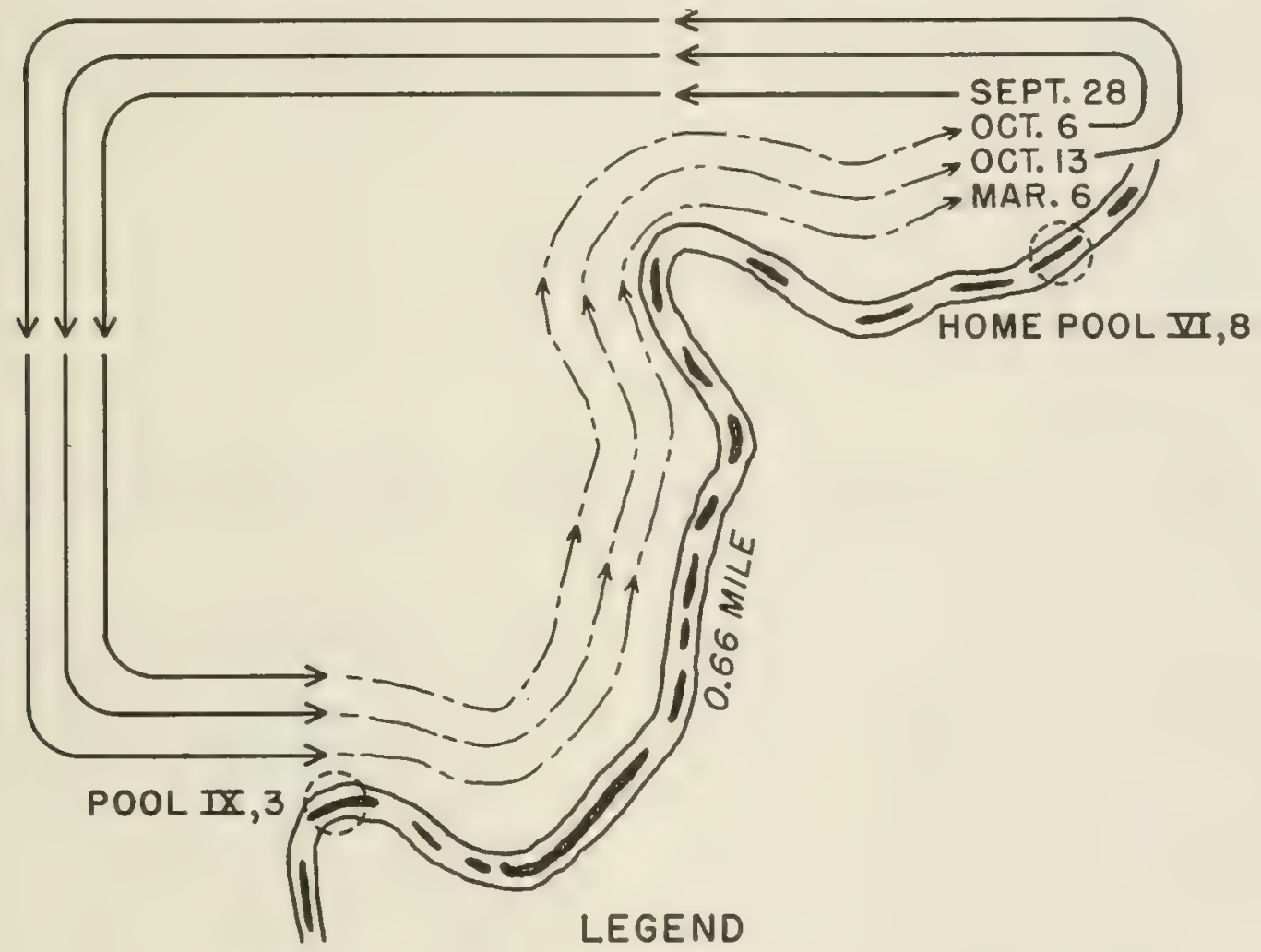

TRANSPORTATION OF TAGGED FISH BY TRUCK

_- - MOVEMENT OF TAGGED FISH WITHIN STREAM

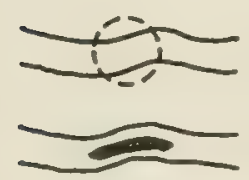

COLLECTING STATION

BASS POOL

Fig. 4. - Section of Jordan Creek, showing the successive overland transters and subsequent movements of a smallmouth bass (No, 147) used in Experiment A.

unnecessary to discuss the movement of individual fish. When the home pool was examined 2 weeks after the transfer, three of the seven bass were recaptured, four were not, fig. 3. Even though less than half of these fish were retaken after 2 weeks, the experiment proves that bass can and will return upstream to a home pool. It seems quite smallmouth bass were taken, of which 7 bore the fin-clip mark of the home pool and were of sizes corresponding to the seven tagged fish that had been moved downstream in 1950. Although none of these 7 bass bore tags when taken in 1951, some of them may have been the fish tagged and moved the previous year. 


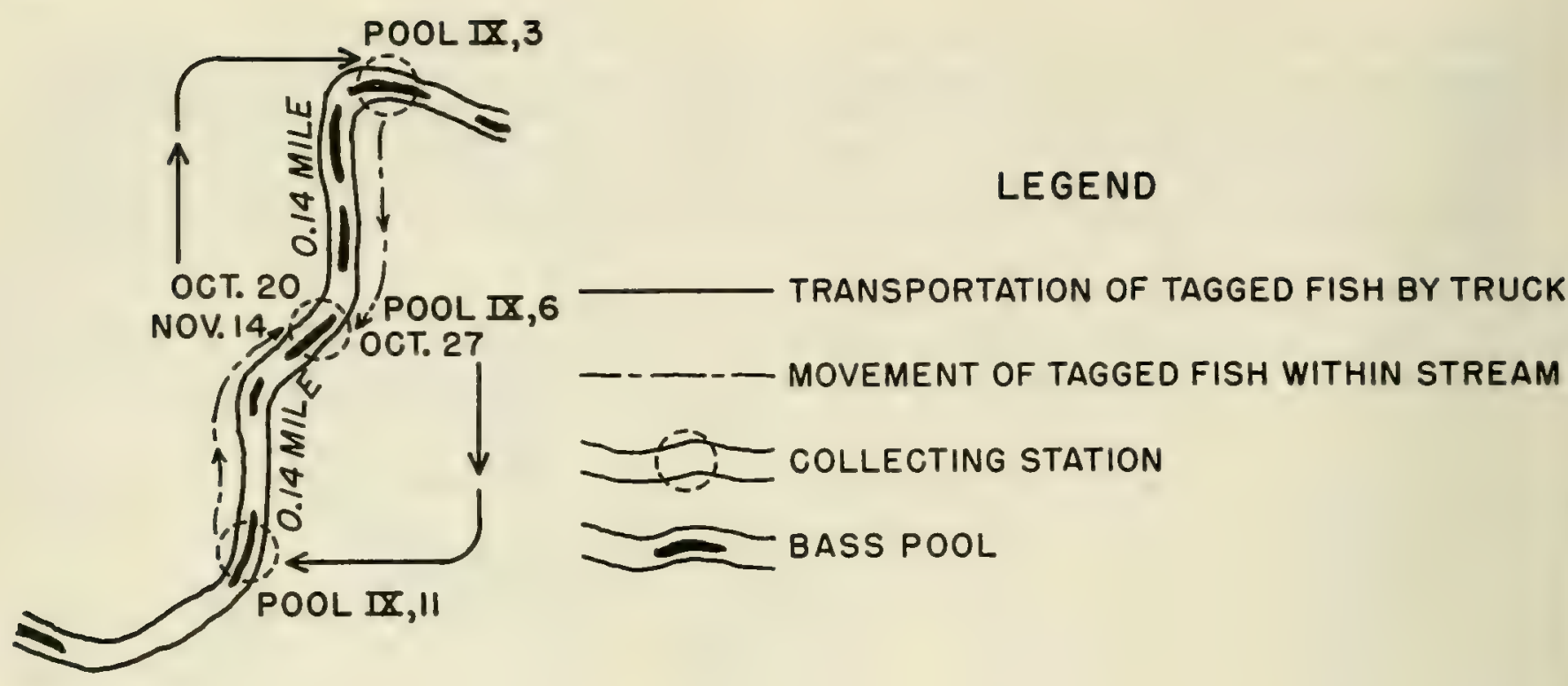

Fig. 5. - Section of Jordan Creek, showing the successive overland transfers and subsequent movements of a smallmouth bass (No. 14205) used in Experiment C.

\section{Experiment C}

Smallmouth bass were moved both downstream and upstream in this experiment to test further the ability of these fish to return to their home pools in either direction.

The experiment was started September 27, when one 7 -inch smallmouth was taken from pool IX, 6, and moved 0.14 mile downstream to pool IX, 3, figs. 1 and 3 . Between these two pools were three riffles and two long pools. Three weeks later, October 20, this bass was recaptured in its home pool, and, with five others $(13.9,7.2,9.0$, 11.8 , and 7.0 inches in length) found there, was moved to the downstream pool, IX, 3. On October 27, 1 week later, only one of these bass, No. 14205 , had returned to pool IX, 6, fig. 5. It was transferred with three others $(9.0,6.9$, and 6.8 inches in length) 0.14 mile upstream and released in pool IX, 11. Five shallow riffles and four pools, one of these poo!s especially suitable for bass, separated the two points. Two of the four bass, including No. 14205, were recaptured in the home pool, IX, 6, on November 14. The following spring, May 18, 1951, two more of the first downstream transfers were retaken; one was in its home pool and one was halfway between its home pool and the point of release.

Following is a summary of Experiment $\mathrm{C}$ :

One smallmouth was moved downstream twice and it returned once.
One was moved downstream once and it returned once.

One, No. 14205, was moved downstream once and it returned once, and then was moved upstream once and it retumed once, fig. 5.

One was moved upstream once and it returned once.

Three were moved downstream and they did not return.

Two were moved upstream and they did not return.

Four of the five fish that did not return had not been taken previously in the section of the stream in which pool IX, 6, was located; two of them had never been marked and two had been marked farther upstream. These four were under 9.1 inches in total length. Because the bass in this experiment were particularly slow in returning after the downstream transfer, probably because of the onset of winter conditions, there was opportunity to move only one fish in both directions, downstream and then upstream. This fish displayed a perfect response, returning to its home pool promptly from both directions, fig. 5 .

\section{Additional Evidence on Homing}

Without becoming much concerned with another species, it is of interest to compare a few 
observations on the movernents of transferred longear sunfish, Lepomis megalotis (Rafinesque), with those of smallmouths. Twenty-four longears were trucked upstream 0.66 mile along with the smallmouth bass in Experiment A. Of these longears, two were recaptured 2 weeks later in their home pool. Three weeks after the transfer, four were still present in the upstream pool. One was caught the following spring, May 17, 1951, halfway between the two pools. Eleven longear sunfish were moved downstream with the bass in Experiment C. Four weeks later, three of the longears were found back in their home pool and one was found in the pool in which it had been released. Later, 15 longears were transferred upstream with the bass in Experiment $\mathrm{C} ; 2$ weeks after the transfer, 4 of the longears were found in their home pool and 4 in the upstream pool.

The lower capacity of the longear to find its way back to a home pool, as compared with that of the smallmouth, may be due to a less highly developed homing tendency in the longear or to other differences in the physical and physiological characteristics of these two species. The longear and the smallmouth are quite different both in body form and in general behavior. The smallmouth is a strong and active swimmer, whereas the longear appears to be relatively sedentary. Gerking (1950) recognized this difference. He found that the longear sunfish showed a strong tendency to remain in the same place, but that the smallmouth bass moved around more than any other species under consideration. Even though the longears of Jordan Creek displayed some homing ability, their return to a home pool was slower than that of the bass. This slow return may account for the low percentage of sunfish recaptures in home pools. If the sunfish, in exhibiting homing tendencies, moved slowly, these fish might have been between the points of release and the home pools when the home pools were being inventoried and might thus have escaped being collected. The conclusion suggested here is that, even though both species have homing tendencies, the swimming strength of the smallmouth may account for its more prompt return to a home pool.

\section{Low Water Levels as a Barrier to Movement}

Low water levels may create a barrier to the homing movements of fish in a small stream such as Jordan Creek. Evidence supporting this assumption was obtained in the summer of 1951 when, on August 10, seven smallmouths were taken from pool $V, 5$, and transferred 0.60 mile upstream to pool VI, 8. At this time the water level in the stream was low, and many of the riffles were covered by less than 2 inches of water. On August 24 , after 2 weeks of continued low water, the home pool of the seven smallmouths was examined. None of the transferred bass was recaptured. On August 29, local rains raised the water level in the creek a few inches and this rise held for a 24-hour period, when the water again dropped to the former low level and remained low for 7 more weeks.

On September 28, 7 weeks after the fish were moved upstream, the home pool was reworked; ap. parently only one bass had returned. About the same time, September 27, the pool that had received the transferred bass also was examined; two of the seven bass were recaptured there, and they were still there on October 17. Both of these fish had been marked in their home pool the year previous to their transfer.

Because the movements of these seven transferred smallmouths are still being followed, only tentative conclusions about them can be drawn now. From these tentative conclusions, which are quite different from those of Experiments A, B, and C cited above, three statements can be made at this time: There was no return to the home pool prior to a temporary rise of the stream; after the rise, occurring 19 days after transfer, the percentage of returns was low (one of seven fish); there was a greater tendency for the bass to remain at the new place of release (two of seven fish) than in the earlier experiments.

The extended period of low water was the only apparent influence that upset the retum of these bass to their home pool. Shallow riffles would have been difficult and dangerous for them to pass. After having been confined to a new area by low water, their drive to return to the home pool may have been lost or reduced to such a level that they were satisfied to remain in a new territory.

\section{Discussion}

In the Jordan Creek homing experiments with smallmouth bass, certain important limitations should be recognized.

1. The calculated rate of return of smallmouth bass to their home pools may have been lower than the actual rate of return for the following reasons:

a. As determined by repeated tests, under average conditions the efficiency of the electric seine in collecting smallmouth bass in Jordan Creek ranged from 65 to 80 per cent in individual 
pools. If one of every three or four transferred fish escaped recapture, the percentage of these fish that actually returned to home pools was considerably greater than the data indicate.

b. At times, high water and turbidity reduced efficiency of the electric seine below average.

c. The number of times pools could be rechecked was limited by practical considerations. Chances of recovering returned fish would have been increased with a larger number of rechecking operations. Formation of ice on Jordan Creek put an abrupt end to rechecking in November, 1950.

d. Some transferred fish may have returned to home pools and have been recovered without being recognized. Circumstantial evidence was found that indicated some transferred fish had lost opercular tags. However, no fish was collected that showed direct evidence of having recently lost a tag, and several fish retained tags through the winter.

2. The mortality rate of the experimental fish was not known. Undoubtedly, some fish suffered natural deaths, and some may have been taken by anglers or have died from injuries received while being collected and tagged. However, the stream was fished very little during the experimental period, and there was no direct evidence of mortality from handling.

3. The number of smallmouth bass used in each experiment was small, mainly because a single pool in such a small stream could not support many large fish. Because of this situation, the response of each fish was emphasized more than if a larger sampling had been possible.

In this study, the strength of the homing behavior and attachment to home pools was judged by the percentage of transferred smallmouths that returned to their home pools, the speed of their return, and the number of times individual fish exhibited successive homing movements. Consideration was given to a number of factors believed to influence homing behavior in fish: direction of movement (upstream or downstream), water level, size of fish, and available habitat. As the transfer experiments were conducted only in the fall, the influence of time of year was not measured. Conceivably, different results might have been obtained at other seasons.

Of the 23 smallmouth bass used in Experiments $A, B$, and C, 12 (52 per cent) displayed positive homing responses. The direction a fish had to take (upstream or downstream) to return to its home pool did not appear to influence homing behavior.

The effect of low water on homing behavior was observed in 1951 when movement of transferred smallmouths was impeded by the shallowness of the riffles in some sections of Jordan Creek. Apparently, fish were unable or unwilling to navigate the stream between the pool to which they had been transferred and their home pool. Thompson (1933) suggested that the random movements of the fish he studied may have reflected in some degree the effects of the drought prevailing at the time of his investigation. His observations are worth noting here, even though neither the types of stream nor the species he studied are comparable to those of the Jordan Creek experiments. To what extent water levels different from those in Jordan Creek at the time of the 1950 and 1951 experiments might have modified the homing behavior of the fish is a subject for speculation and further investigation.

Large fish displayed stronger homing tendencies than small fish. Of the 11 smallmouths that failed to return to the pools from which they had been removed, 7 had not been taken previously in the particular sections of the stream in which the pools were located. This evidence may indicate that some of the smallmouths in any pool may be only temporary residents and therefore should not be expected to return. The fact that five of these seven fish were 9.0 inches or less in total length suggests that the small immature fish tend to wander more than larger ones. Of the eight small bass used in the three experiments, only three were recovered from pools assumed to be their home pools. These three were the only bass of small size that had been taken previously in the stream sections from which they were transferred.

The influence of size of fish is especially evident in the results of Experiment A. No smallmouths of less than 10 inches were used in this experiment. Five of the seven smallmouths returned at least once to their home pool. Of 13 transfers made from this pool, 9 ( 69 per cent) were followed by homing responses. This rate of return is considerably higher than that for the combined experiments, 55 per cent (17 returns from 31 transfers), table 2.

Homing, as demonstrated in these experiments, cannot be explained simply as a random locating and claiming of suitable available territory. If it could, the large domineering fish would have been likely to establish new territories before returning to their home pools, as most returning individuals passed through many pools suitable for smallmouths before reaching their home pools. These experiments showed that the tendency to return to home pools was stronger among these large fish than among smaller individuals. 
Table 2. - Returns of smallmouth bass transferred one, two, or three times in Jordan Creek Experiments $A, B$, and $C$.

\begin{tabular}{l|c|c|c|c|c}
\hline \multirow{2}{*}{ Transfer } & $\begin{array}{c}\text { Number of Bass } \\
\text { Transferred }\end{array}$ & $\begin{array}{c}\text { Number of Bass } \\
\text { Retaken in Pool } \\
\text { of First Capture }\end{array}$ & $\begin{array}{c}\text { Number of Bass } \\
\text { Never Retaken }\end{array}$ & \multicolumn{2}{|c}{$\begin{array}{c}\text { Number of Bass } \\
\text { Retaken in Pool } \\
\text { Other Than Pool } \\
\text { of First Capture }\end{array}$} \\
\cline { 3 - 6 } & 23 & 12 & 11 & $\begin{array}{c}\text { Point of } \\
\text { Release }\end{array}$ & $\begin{array}{c}\text { Other } \\
\text { Pool }\end{array}$ \\
\hline First & 7 & 4 & 0 & $2^{+}$ & $1^{*}$ \\
Third & 1 & 1 & 0 & $2^{+}$ & 0 \\
All & 31 & 17 & 11 & $3^{+}$ \\
\hline
\end{tabular}

*Fish was retaken later in home pool.

${ }^{+}$One of these fish was retaken later in home pool.

How homing ability in the smallmouth bass functions is at present unexplained. A response to some taste-odor or physical condition of the water would not direct return of the fish both upstream and downstream. It seems unlikely that a transferred fish locates its home pool simply by random movements along the stream, wandering until it comes to its home territory and then in some way recognizing this territory. Such a trialand-error behavior would cause more delay in returning than was shown by most of the transferred bass.

\section{Summary}

1. The possibility that smallmouth black bass, Micropterus dolomieu, establish home pools was investigated in Jordan Creek in east-central Illin ois.

2. Of the smallmouths that had been fin-clipped during a preliminary census of Jordan Creek, 80 per cent of those retaken the same year and 67 per cent of those retaken the following year were in the sections of the stream in which they had been originally marked. Sixty per cent of the smallmouth bass that were recaptured after having been marked with numbered tags were in the identical pools in which they had been tagged.

3. Smallmouths transferred overland and released in other parts of the stream showed an ability to return to their home pools. They returned from either upstream or downstream. Twenty-three bass were involved in 31 transfers. Of these 31 transfers, 17 ( 55 per cent) were followed by homing responses. Four of seven fish that were moved twice returned a second time to their home pools.
One fish was moved three times and returned three times to its home pool.

4. Evidence indicated that certain smallmouths in any pool were only temporary residents and that those of 9.0 inches or less in total length tended to wander more than larger ones.

5. Smallmouth bass transferred during a period of low water levels tended to remain at the place of release, possibly because of the difficulties in passing shallow riffles.

6. Some evidence of homing behavior in longear sunfish was obtained, although the response was slower and less certain than for bass.

\section{Acknowledgments}

This study is a contribution from a stream research project supported jointly by the Illinois Department of Conservation and the Illinois Natural History Survey. Mr. Leonard Durham and Mr. Quentin H. Pickering, employed by the Department of Conservation, assisted in the field work. Dr. George W. Bennett and Dr. Donald F. Hansen, both of the Natural History Survey, made suggestions for preparation of the manuscript. The manuscript was edited by Mr. James S. Ayars, Technical Editor of the Survey.

\section{Literature Cited}

Funk, John L.

1949. Wider application of the electrical method of collecting fish. Am. Fish. Soc. Trans. for $1947,77: 49-60$. 
Gerking, Shelby D.

1950. Stability of a stream fish population. Jour. Wildlife Mgt. 14(2):193-202.

Rodeheffer, Immanuel A.

1941. The movements of marked fish in Douglas Lake, Michigan. Mich. Acad. Sci., Arts, and Letters Papers 26:265-80.

Schuck, Howard A.

1945. Survival, population density, growth, and movement of the wild brown trout in Crystal Creek. Am. Fish. Soc. Trans. for $1943,73: 209-30$.
Scott, Donald C.

1949. A study of a stream population of rock bass, Ambloplites rupestris. Ind. Dept. Cons. and Ind. Univ. Invest. Ind. Lakes and Streams 3(3):169-234.

Shetter, David S.

1937. Migration, growth rate, and population density of brook trout in the north branch of the Au Sable River, Michigan. Am. Fish. Soc. Trans. for 1936, 66:203-10.

Thompson, David H.

1933. The migration of Illinois fishes. Ill. Nat. Hist. Surv. Biol. Notes 1. 25 pp. 


